\title{
Development of a Patient Decision Aid for the Treatment of Osteoporosis Among Filipino Postmenopausal Women
}

\author{
Ma. Carrissa Abigail Roxas, ${ }_{1}^{1}$ Cecilia Jimeno, ${ }^{1,2}$ Lia Palileo-Villanueva, ${ }^{2}$ Anna Angelica Macalalad-Josue, ${ }^{1}$ \\ Mark Anthony Sandoval, ${ }^{1}$ Jose Alberto Fernandez ${ }^{3}$
}

${ }^{1}$ Division of Endocrinology, Diabetes and Metabolism, Department of Medicine, University of the Philippines - Philippine General Hospital, Philippines ${ }^{2}$ College of Medicine, University of the Philippines Manila, Philippines

${ }^{3}$ University of the Philippines Diliman, Quezon City, Philippines

\begin{abstract}
Background. Guidelines for osteoporosis have provided recommendations on when to offer pharmacologic management for postmenopausal women, but do not specify which "best" medication to start. The choice of therapy depends on the efficacy, safety/tolerability of the drug and the patient's profile and preferences. Patient decision aids (PtDA) are tools designed to facilitate shared decision-making (SDM) between the patient and health care provider for conditions where there are several available options, and the "best" choice is unclear. We aimed to develop a culturally acceptable patient decision aid on the treatment of osteoporosis among Filipino postmenopausal women at risk of osteoporotic fractures.

Methodology. A qualitative approach and an iterative process was employed in this study following the guidance of the International Patient Decision Aid Standards (IPDAS). Phase 1 (Needs Assessment) involved interviews with 8 physicians who are involved in the care of women with osteoporosis and focus group discussions with 19 postmenopausal women with osteoporosis who have received treatment. Phase 2 (PtDA Development) involved a systematic review of evidence and development of an initial prototype through several iterations with an expert panel. The final prototype was pilot tested in actual clinical encounters (Phase 3).

Results. The final PtDA consists of 6 laminated flashcards, which illustrate the different considerations that are important to patients when selecting an anti-osteoporosis treatment (efficacy, method, frequency of administration, side effects and cost), and a fracture worksheet to illustrate individualized effects of the treatments on the patient's fracture risk. These are accompanied by a clinician guide on how to use the PtDA during consultations, which includes information on non-pharmacologic management of osteoporosis. The PtDA was acceptable to physicians and patients.
\end{abstract}

Conclusion. With the integration of decisional needs assessment, clinical expertise, user preference and iterative revision testing, we were able to develop a culturally adapted PtDA on the treatment of osteoporosis among Filipino postmenopausal woman at risk of osteoporotic fractures for use during clinical encounters.

Key words: patient decision aid, shared decision-making, osteoporosis, treatment

\section{INTRODUCTION}

Osteoporosis remains a growing health problem in a population that is aging. With the growing population, the number of Filipinos at high risk of osteoporosis is projected to reach 4 million by 2020 and 10.2 million by $2050 .{ }^{1}$ As such, the burden of osteoporosis-related fractures cannot be underrated since it leads to diminished quality of life, disability and death. These fracture risks, along with its associated morbidity and mortality, can be reduced with early identification and treatment of patients at risk of osteoporosis.

Pharmacologic therapy in the prevention of postmenopausal osteoporosis fracture consists of antiresorptive agents (bisphosphonates, estrogens, selective estrogen- receptor modulators, denosumab) and an anabolic agent (teriparatide). ${ }^{2}$ Despite the availability of these effective medications, there remains a treatment gap in the management of osteoporosis. Cited reasons were failure of the physicians to prescribe medications; if prescribed, patients were not taking it at all. ${ }^{3}$

Guidelines recommend when to offer pharmacologic management, but it has not clearly stated which "best" medication to start. ${ }^{4}$ The available treatments have similar efficacy, but have different routes of administration, dosing regimens, prices and clinical safety profiles. ${ }^{2}$ Patients who are advised to initiate therapy in osteoporosis are placed in a preference-sensitive situation because more than one treatment option exists. The decision as to which medication to choose is a complex one, and is
ISSN 0857-1074 (Print) I eISSN 2308-118x (Online)

Printed in the Philippines

Copyright (C) 2020 by Roxas et al.

Received: September 9, 2019. Accepted: October 20, 2019.

Published online first: May 23, 2020.

https://doi.org/10.15605/jafes.035.01.15
Corresponding author: Ma. Carrissa Abigail R. Roxas, $M D$

Division of Endocrinology, Diabetes and Metabolism

Department of Medicine, University of the Philippines-Philippine General Hospital Taft Avenue, Ermita, Manila, Philippines 1000

Tel. No.: +632-554-8400 local 2230

E-mail: abiroxas@gmail.com

ORCiD: https://orcid.org/0000-0002-2864-2879 
usually based on what the patient values the most. ${ }^{5}$ In a six-month, prospective, randomized, open label study comparing once monthly ibandronate $150 \mathrm{mg}$ versus weekly alendronate $70 \mathrm{mg}, 66.1 \%$ preferred once a month treatment with ibandronate due to ease of following the treatment regimen. ${ }^{6}$ Issues on the cost of treatment and side effects also affect treatment outcomes, as these are the common reasons for discontinuation of treatment. ${ }^{7}$ Due to the variations in preferences of patients, physicians should incorporate them in the decision-making process in order to ensure successful treatment of this long term condition, since poor adherence could be a result of unmet preferences. ${ }^{8}$

Shared decision-making, wherein the physicians "understand patient goals and priorities, incorporate clinical and patient priorities, and address obstacles to care" may help patients arrive at a decision that is consistent with their preference. ${ }^{9}$ In order to engage patients towards SDM, it is important that evidence be translated into a simple, easy-to-understand format containing important points needed to come up with a decision that is in line with their values. ${ }^{10}$ Patient decision aids are evidence-based tools that support SDM. They are intended to: 1) increase the patient's knowledge and understanding of the disease and its associated risks using plain language that is easy to comprehend by the general population, 2) provide structured guidance in making decisions consistent with the patient's values, and 3) improve the quality of the decision-making process. Their use has enhanced patientdoctor communication and has reduced the proportion of people who remained undecided post-intervention. ${ }^{11}$

Currently, there are existing PtDAs on the initiation of treatment of osteoporosis. These aids have been found to increase in transfer of knowledge, decrease decisional conflict and improve patient involvement in the decision- making process. However, its impact on treatment adherence in the long run remains to be determined. ${ }^{12-14}$

To date, there is no existing PtDA tailored for Filipino postmenopausal patients with osteoporosis who have opted to initiate treatment. The development of a PtDA that is simple to use and easy to understand could potentially improve SDM in the treatment of osteoporosis. The primary objective of the study was to develop a culturally adapted PtDA to help Filipino postmenopausal women who have decided to initiate osteoporosis treatment choose which treatment to start. Moreover, the study aims to describe the decision support needs of physicians and postmenopausal women regarding the treatment of osteoporosis, and to present in detail the systematic manner on how the patient decision aid was developed.

\section{METHODOLOGY}

\section{Study setting and population}

A qualitative design using an iterative approach was employed from July 2018 to June 2019 at the outpatient department of a tertiary government hospital in Manila, Philippines that mostly caters to patients from low income families.

The methodology was guided by the International Patient Decision Aid Standards (IPDAS) providing developers with quality standards regarding PtDA content and development process. ${ }^{15}$ The study involved 3 phases: Phase 1, needs assessment; Phase 2, development of the PtDA; and Phase 3, pilot testing of the PtDA in an actual clinical encounter (Figure 1).

The protocol was approved by the University of the Philippines Manila Research Ethics Board (UPM REB 2018-117-01) prior to the initiation of the study.

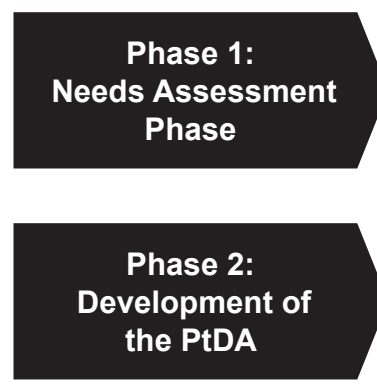

\section{Assess patient's views on decisional needs (Focus group discussion with patients who received treatment for their care)}

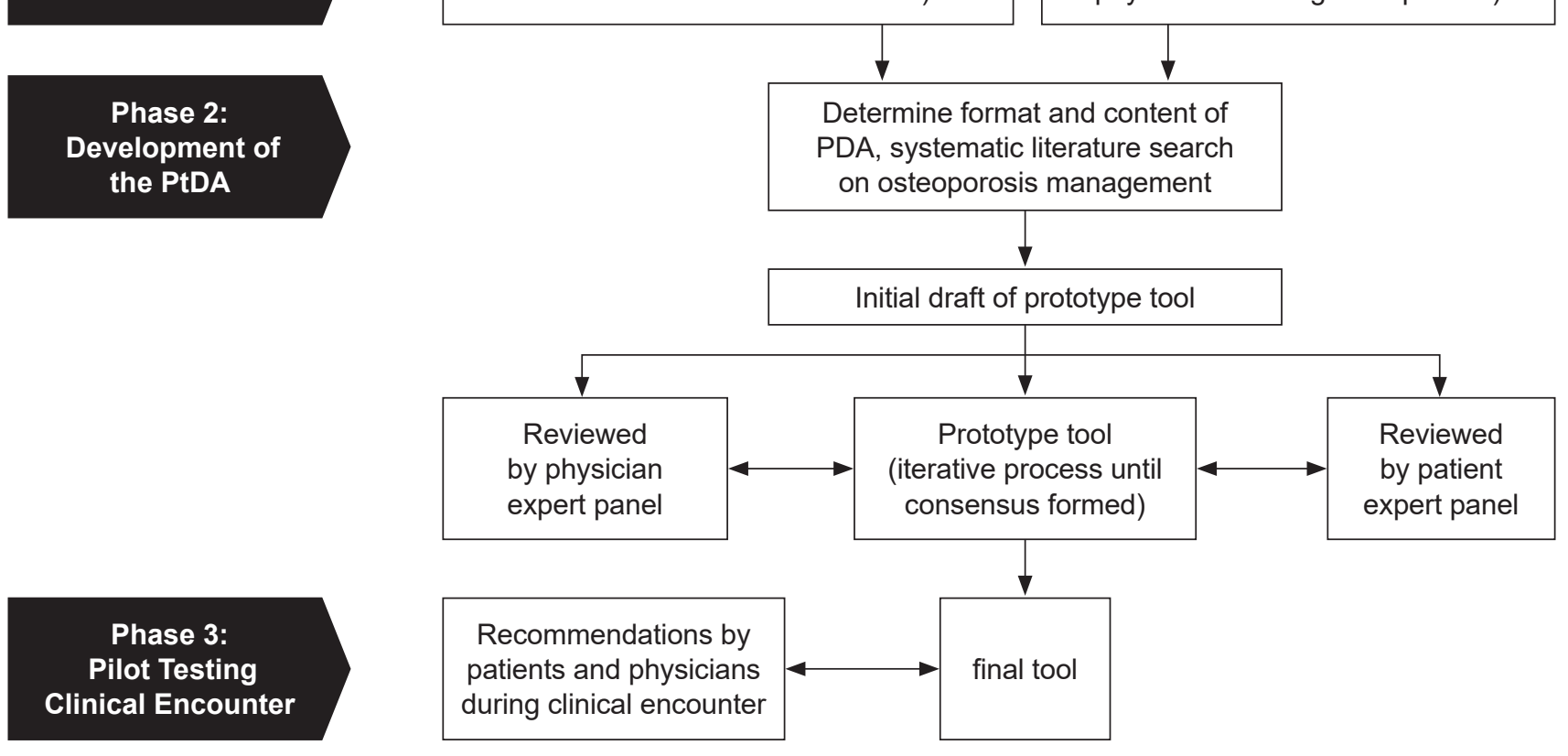

Assess physician's views on decisional needs (Key informant interviews with physicians treating osteoporosis)

Figure 1. Flow diagram of the steps in the development of the patient decision aid. 


\section{Phase 1: Needs Assessment}

A needs assessment was performed to elicit views of physicians and patients on the challenges and resources that helped them with making decisions in the treatment of osteoporosis.

\section{A. Key informant interviews with physicians}

Key informant interviews with 8 physicians from different services involved in the care of osteoporosis (endocrinology, rheumatology, orthopedics, family medicine and internal medicine) were conducted by the primary investigator using a semi-structured questionnaire. Interviewees were selected through convenience sampling and an informed consent was obtained prior to the interview. The interviews covered the perceived challenges postmenopausal women face in making decisions on osteoporosis treatment, and the potential usefulness of PtDA in facilitating these discussions. All interviews were audio taped. The recorded interviews were transcribed, analyzed and summarized into themes.

\section{B. Focus group discussions (FGD) among post- menopausal patients}

FGDs among postmenopausal patients who received treatment for their care were conducted to obtain information on the osteoporosis treatments they received at diagnosis, the information they wished they had known before making a decision, their opinions about their participation in decision-making, and their views on the use of PtDA. Nineteen postmenopausal patients who satisfied the inclusion criteria were recruited via convenience sampling from the Endocrinology outpatient clinics of the Philippine General Hospital and participated in one of the 2 focus group discussions. Inclusion criteria were: (1) postmenopausal women 50 years of age and above, (2) have experienced medical treatment for osteoporosis aside from calcium and/or vitamin D, (3) able to participate verbally in a group discussion, and (4) fluent in Filipino. Informed consent was obtained prior to starting the FGDs. The FGDs were conducted in a quiet room to ensure privacy, video recorded, and transcribed verbatim.

\section{Phase 2: Development of the PtDA}

An iterative process was employed in designing the PtDA. First, evidence on the effectiveness and safety of the different osteoporosis treatments were reviewed and summarized. Second, a prototype PtDA was designed that contained information on the route of administration, method of administration, efficacy, safety and cost of the osteoporosis drugs. This was shown to expert panels that included physicians (a rheumatologist, geriatrician, an orthopedic surgeon who is the head of the Fracture Liaison Service of the hospital, and a family medicine physician who has experience in developing a culturally adapted PtDA on diabetes) and patients to obtain feedback on appearance, understandability, content, ease of use. Finally, the PtDA was revised according to the feedback. This process was repeated until no new feedback was obtained.

\section{Phase 3: Pilot Testing in an Actual Clinical Encounter}

Six physicians, who were knowledgeable in osteoporosis medications, and were not part of the expert panel, were selected via convenience sampling and oriented on the nature of the study. The prototype PtDA was tested in 6 actual clinical encounters among 6 postmenopausal patients who were candidates for the treatment of osteoporosis in order to obtain feedback on the length, appearance, understandability, content, ease of use and acceptability of the PtDA. Recommendations for improvement were also inquired. The PtDA was then revised according to the feedback obtained from the interviews and the process was repeated, each time with new patients, until no further revisions were needed.

\section{RESULTS}

\section{Phase 1: Needs Assessment}

\section{A. Key informant interviews with physicians}

Key informant interviews were conducted among 8 physicians who were from endocrinology $(n=4)$, rheumatology $(n=1)$, orthopedics $(n=1)$, family medicine $(n=1)$ and adult medicine $(n=1)$. The main focus of the interviews were challenges postmenopausal women face in making decisions on osteoporosis treatment, and the potential usefulness of PtDA in facilitating these discussions.

\section{Initiation of treatment}

Once physicians diagnosed their patients with osteoporosis, there were no issues in initiating pharmacologic management to the patients. Majority of the physicians offer treatment options to the patients, mostly starting with alendronate due to its availability, ease of administration and cost. They discuss the other forms of medications in passing, focusing more on the frequency of administration and cost.

\section{Physicians' priorities}

The top consideration of physicians when initiating treatment is cost. Since most of their patients are from families of low socioeconomic status, the physicians did not offer the other medications, such as denosumab and teriparatide, due to their perceived limited financial capacity of their patients. On the other hand, 2 physicians offer these medications because of available support from funding agencies. Accessibility is another consideration, as other medications aside from bisphosphonates are usually not available in pharmacies. In contrast, 2 physicians offer only alendronate. The first physician acknowledged unawareness of the newer medications in the market, while the other physician found it difficult to present all the options to his patients due to time constraints.

\section{Use of PtDA in osteoporosis}

When a locally adapted PtDA on diabetes was shown to the physicians, all were receptive to using a similar tool when discussing treatment options for osteoporosis with their patients. Reasons cited include the usefulness of the PtDA in: (1) facilitating and shortening the discussion on treatment options because the important points are already provided, (2) helping patients understand the information better than just listening to a verbal explanation, and (3) engaging the patient in a conversation. In addition, physicians also consider efficacy, method and frequency of administration, cost and side effects as important issues in initiating treatment. One physician emphasized that for the tool to be effective, the patient has to be willing to participate in decision-making, as there are some who would leave the decision to their physicians. 


\section{B. Focus group discussion with patients}

Nineteen postmenopausal patients who received treatment for osteoporosis participated in the FGD. The average age of the participants was 66 years (range, 51 to 94 years), while the average time on treatment with an antiosteoporosis drug was 17 months (median, 12 months; range, 1 to 60 months). More than half of the participants were on alendronate (11/19) followed by zoledronic (5/19), while 3 patients were using denosumab. Majority of them finished high school and college, while 5 patients completed elementary school. All of the patients had a household income of less than PhP 15,000/month (Table 1).

\begin{tabular}{lc}
\multicolumn{2}{l}{ Table 1. Characteristics of focus group discussion patient } \\
participants \\
\hline Characteristic & $\begin{array}{c}\text { Total } \\
\mathbf{n}=19\end{array}$ \\
\hline Mean age, year & 66 \\
Mean age at diagnosis, year & 64 \\
Medication timeline, month & 17 \\
Medications taken & \\
Alendronate & 11 \\
Zoledronic acid & 5 \\
Denosumab & 3 \\
Education & \\
No formal education & 0 \\
Elementary school & 5 \\
High school & 7 \\
College degree & 7 \\
Postgraduate degree & 0 \\
Vocational & 0 \\
Employment & \\
Employed & 4 \\
Retired \\
Household income per month & 15 \\
Less than PhP 15,000 & \\
PhP 15,000 to 30,000 & 19 \\
PhP 30,000 to 45,000 & 0 \\
PhP 45,000 to 60,000 & 0 \\
More than 60,000 & 0 \\
\hline & 0 \\
\hline
\end{tabular}

\section{Osteoporosis consultation}

Once patients were diagnosed with osteoporosis, majority based on bone densitometry, their physicians offered pharmacologic treatment to prevent fractures. There was no difficulty in initiating treatment since most patients understood their condition and the importance of fracture prevention. Pharmacologic options were discussed with the majority of the patients, but a subset (7/19) were not offered options at all. These patients would have wished to be involved in decision-making if given the chance. For patients who were offered pharmacologic management, they were mostly asked to choose among the drugs based on frequency of administration and cost of treatment.

\section{Factors influencing patient choice of osteoporosis treatment} Since most patients pay for their medications out-ofpocket, cost was the main consideration in selecting osteoporosis treatment for majority of the patients (8/19). However, some $(3 / 19)$ were able to procure medications such as denosumab and zoledronic acid from government funding agencies. The next priority of the patients was drug efficacy in terms of preventing fractures. The frequency and convenience of administration of the drug were also important considerations. One patient preferred yearly treatment with zoledronic acid due to polypharmacy and convenience issues. On the other hand, other patients preferred weekly administration due to the fear of a onetime administration of the drug.

\section{Information clarification}

Majority of the patients said they wished they had received more information about the side effects of medications from their physicians. Some reported that it was only after they developed symptoms after taking the drug that they learned that these were actually side effects. Costs of the medications should also have been mentioned during the consultation. One patient emphasized the need to explain how the drug will be administered since only a prescription was given to her.

\section{Use of PtDA in osteoporosis}

A sample of a locally adapted PtDA on diabetes was shown to the patients and they were told that a similar tool will be developed for osteoporosis. Almost all of them were receptive to the idea of incorporating the tool in the consultation. A tool that uses graphics would facilitate their understanding of the information about the different drugs and help them in choosing which medication to start. The content that they wanted to see included efficacy, cost, frequency and method of administration, and duration of treatment. One patient was satisfied with the physician's choice of medication and did not see the need for a PtDA.

\section{Phase 2: Drafting of the PtDA}

\section{A. Prototype development}

We based the content and format of the initial prototype on the information gathered from the needs assessment phase. The included the drugs alendronate, ibandronate, risendronate, zoledronic acid, raloxifene, denosumab and teriparatide, which are all approved by the Food and Drug Administration of the Philippines and locally available. The PtDA was developed as paper-based, laminated flashcards since there is no readily available access to computers in the outpatient clinics in our setting. The flashcards were divided into the priorities of the patients when choosing a drug: efficacy, method of administration, frequency of administration, side effects and cost. The tool is intended to be used during an actual clinical consultation with the physician.

In order to provide quality and up-to-date data, we performed a systematic literature search on different anti-osteoporosis medications. Data on the route of administration and frequency were extracted mainly from the National Osteoporosis Foundation's Clinician's Guide to Prevention and Treatment of Osteoporosis. ${ }^{4}$ The side effects of each class of drug with its corresponding probabilities of occurrence were mainly based on the National Osteoporosis Society's data. ${ }^{16-22}$ A network metaanalysis comparing the efficacy of the different classes of bisphosphonates was the basis for the relative risk reduction in the efficacy card..$^{23}$ Additional data on risk reduction were obtained from the landmark trials of denosumab and teriparatide. ${ }^{24,25}$ Lastly, the range of costs of the different classes of drugs were based on local pharmacy prices.

The flashcards were printed on laminated paper sized 7.5 in $\times 4$ in each. The font sizes were at least 12 pt and non-cursive to allow easy user readability among elderly patients. Dark fonts were contrasted to a white background to allow the eyes to relax. The flashcards were color coded to easily differentiate each aspect of the drug. The researchers also used visual aids in the form 
of icons to communicate information. We also presented information using illustrations as well as pictograms in communicating risks and risk reduction.

\section{B. Iterations with expert panel}

Walkthroughs of the initial prototype were done for the physician and patient expert panels. Each flashcard was discussed including content, design, format, and presentation of data. Revisions were made based on the recommendations of both groups. A total of 4 iterations were performed until the final prototype tool was formed.

During the first iteration, the physician expert panel agreed to use flashcards for ease of access and reproducibility with a larger size format (10.8 in x 5.4 in). Improvements in the presentation of cost, method and frequency of administration were made. We decided to present the 5 most common side effects of the different medications and to arrange it based on frequencies of natural occurrences. Rare side effects such as osteonecrosis of the jaw $(\mathrm{ONJ})$ and atypical fracture were included to offer a balanced presentation.

On the second iteration, the presentation of the efficacy card was changed from the initial bar graph comparing relative risk reduction per medication to a colored pictogram of the spine and hip. Each colored figure represents a $10 \%$ risk of fracture. An introduction card was also added, containing non-pharmacologic osteoporosis prevention. Minimal revisions in grammar and layout were made in the third and fourth iterations.

When shown to the patient expert panel, the tool received positive responses. The group commented that the PtDA was easy to understand, visually appealing, used clear language and was engaging to the patients. They also appreciated the introduction card which contained non-pharmacologic management, as was a frequently asked question among patients. They wished they had a similar tool when they were initially deciding which medication to start.

Several recommendations were made during the discussion. Physicians should have a standardized way of explaining the cards, prompting the development of a clinician's guide. Physicians, when using the PtDA, should clearly communicate the risk of side effects to avoid alarming the patients. A comment was made to include the duration of use of medications, but it was decided that it will be discussed separately by the physician.

\section{Phase 3: Testing in actual clinical scenarios}

The revised PtDA was tested for acceptability among 6 patients who were candidates for treatment and 6 physicians who used it in actual clinical encounters in the outpatient services (Figures 2 to 8). Clinicians were oriented on how to use the PtDA cards prior to use in a patient consultation.

The patients' ages ranged from 56 to 66 years old with varying educational backgrounds, from elementary to college graduates. The physicians were all endocrinologists. The range of time using the tool ranged between 8 to 14 minutes, with an average time of 10 minutes.

\section{A. Patient insights}

Overall, patients were receptive to using the PtDA during clinic consultation. They all agreed that the PtDA made the options more clear and also recommended its use to all candidate patients.

The length of presentation was enough in order to explain the vital information needed by the patients. However, for one patient, it seemed longer than the usual consultation but was "necessary" in order to discuss the medications in detail. Another patient, an elementary degree graduate, had the longest time of presentation of 14 minutes. She needed more time to understand the flashcard on cost because she could not grasp that some of the drugs are paid once a week while the others were once a year.

Moreover, the amount of information was sufficient enough to enable the patients to choose their medication at the end of the consultation. One of the patients appreciated that the aspect of cost was discussed since she was surprised at how much it will cost her in addition to her other maintenance medications (Figure 8). The side effects card was initially intimidating and raised anxiety in some of the patients (Figure 7). One patient had an issue with the rare adverse event of $\mathrm{ONJ}$ from zoledronic acid after seeing the flashcard. However, the patient eventually said she will take the risk after sufficient explanation from the physician about the rarity of ONJ as an adverse event. We observed that the PtDA was able to stimulate conversation between the patient and physician by encouraging patients to ask questions based on the information presented to them. Likewise, it enabled clinicians to clarify important points in the treatment plan.

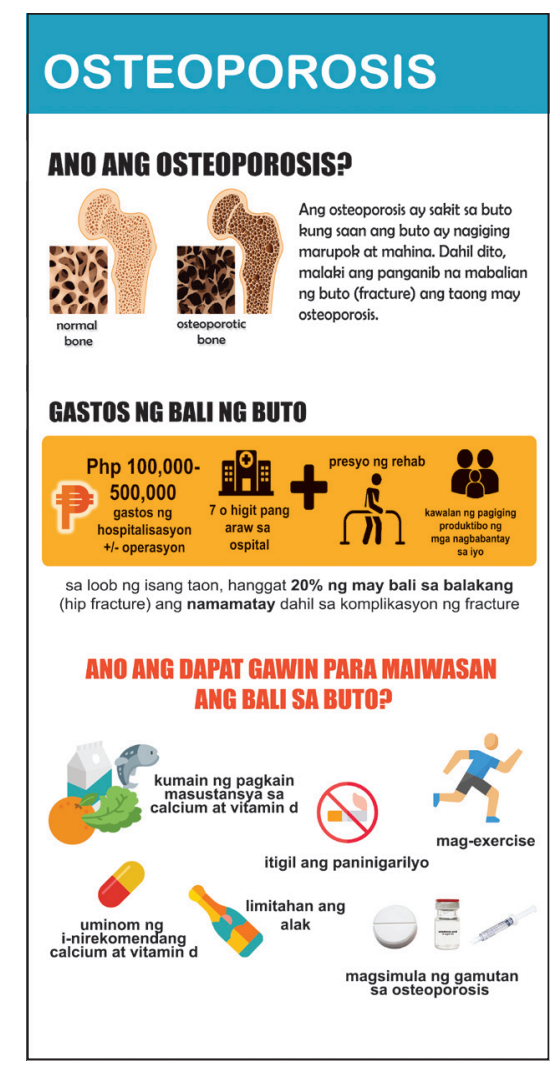

Figure 2. Introduction card on osteoporosis. It contains a brief description of osteoporosis, the cost of having a fracture and an overview of management. 


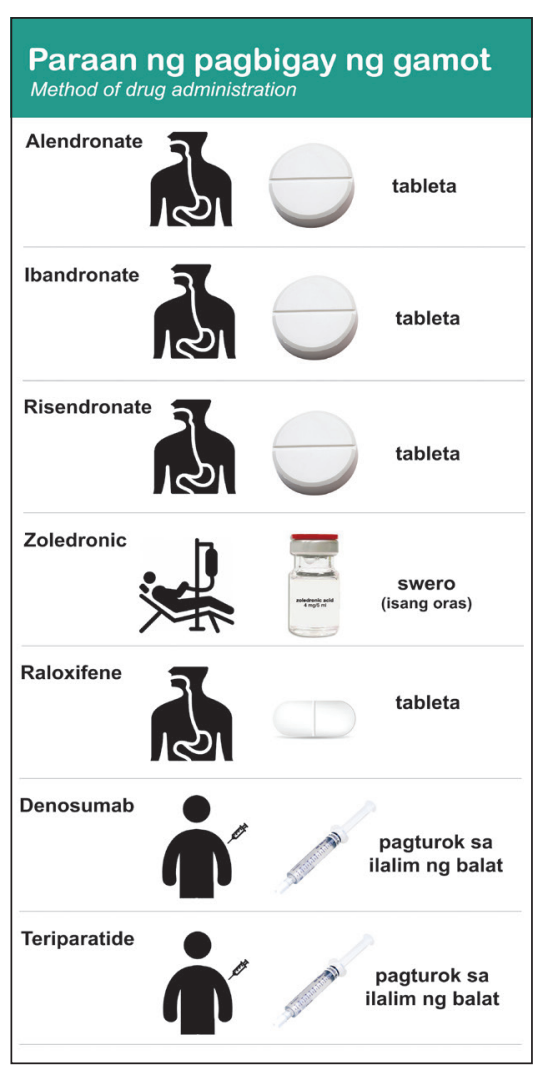

Figure 3. Flashcard on method of drug administration.

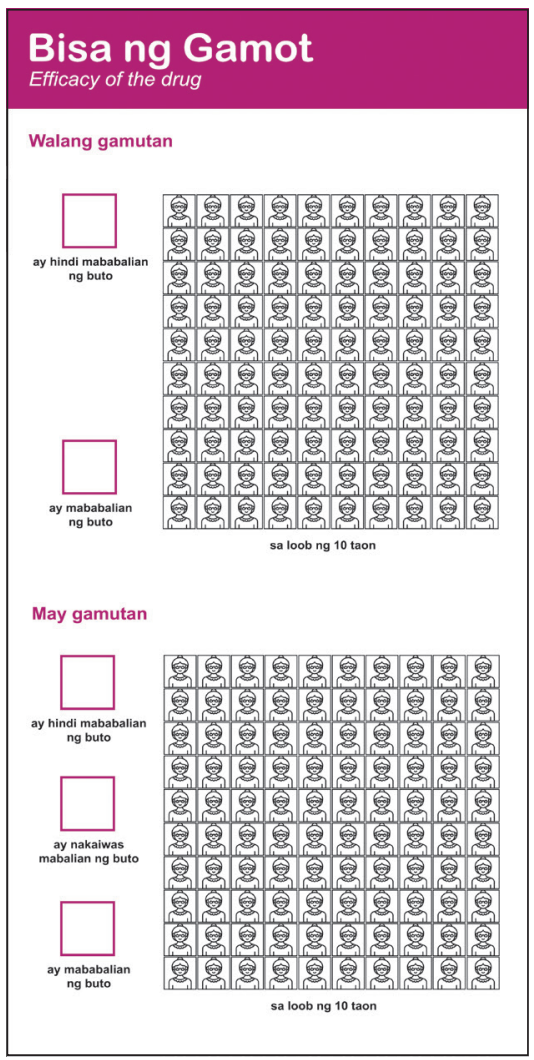

Figure 6. Patient-specific absolute fracture reduction worksheet.

\section{Dalas ng gamutan
frequency of drug administration}

\section{Alendronate}

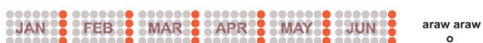

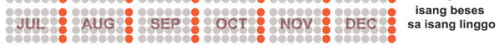
Ibandronate

INAN : Risendronate

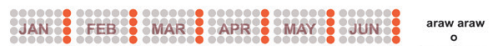

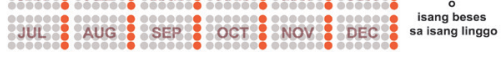
Zoledronic

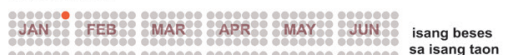

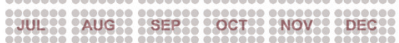

Raloxifene

มับงหมี

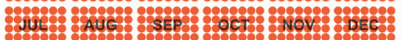

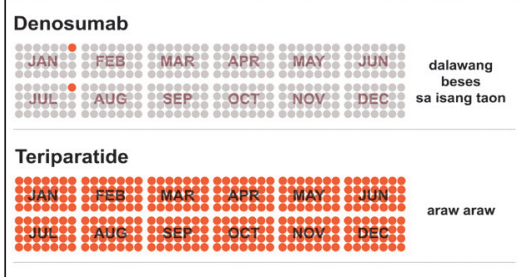

Figure 4. Flashcard on frequency of drug administration.

\section{Side effect}

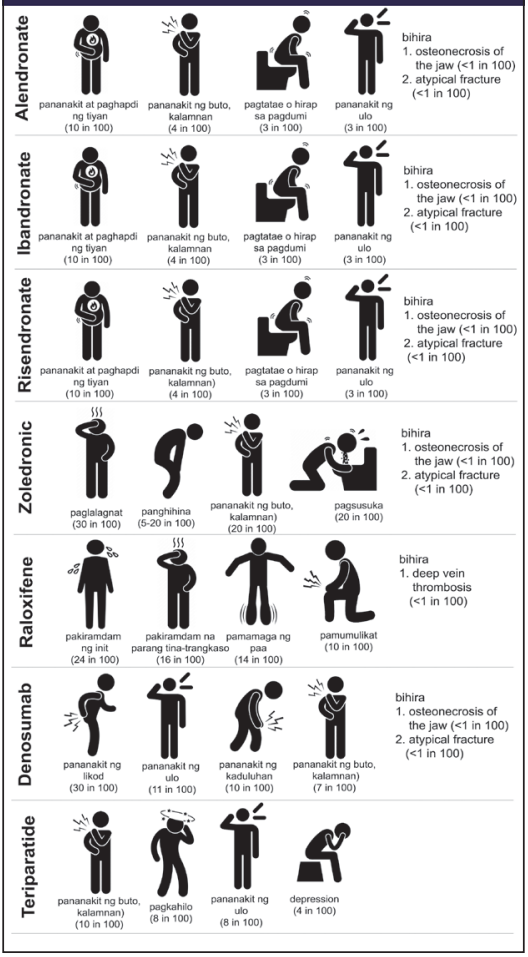

Figure 7. Flashcard on side effects of the different agents.

\section{Bisa ng Gamot}

产 vertera

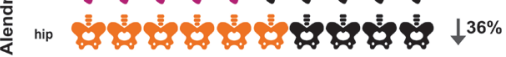
产 童

产veroor $\frac{1}{3}$ 耪

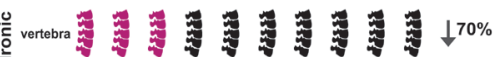
营

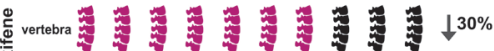
产

兽 hip

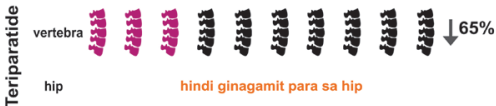

Figure 5. Flashcard on efficacy of other treatments.

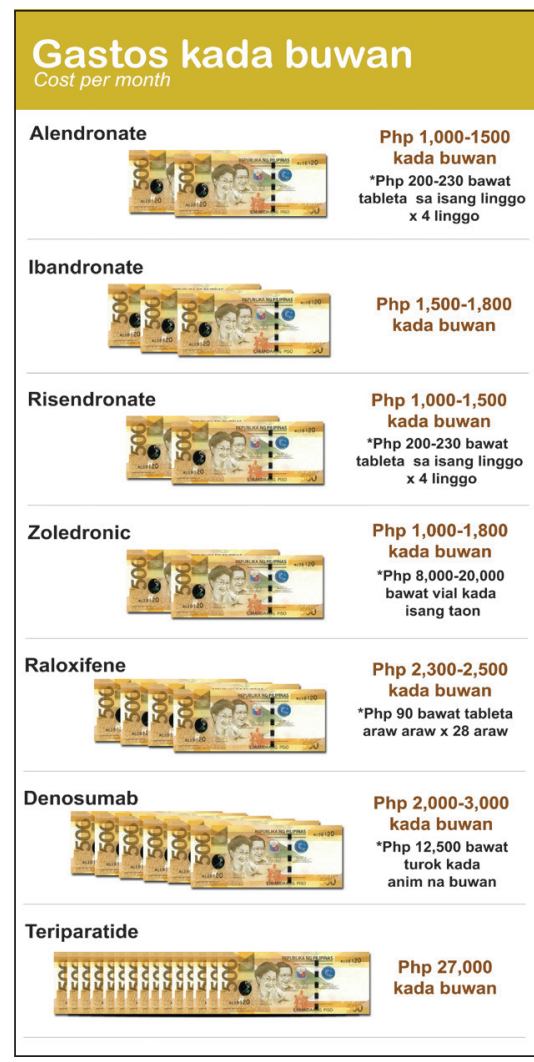

Figure 8. Flashcard on cost of treatment per month. 
Similarly, the patients related that the graphics made it easier for them to understand information on the medications. Although some of the pictograms, particularly the efficacy card, needed more clarification, physicians were able to sufficiently explain risk reduction for patients to understand the concept. Nonetheless, a separate worksheet was added to further illustrate patient-specific absolute fracture risk reduction (ARR) when the medication is taken (Figure 6). Both physicians and patients agreed that this way of presenting ARR more clearly illustrated medication efficacy.

Overall, the patients preferred using the tool over the usual consultation. As one of the patients aptly remarked, "Mas maganda na may nakikita (It's better to have visuals)." A patient also wished that her other doctors had a similar tool to guide her treatment decisions for her other conditions.

\section{B. Physician insights}

Similarly, all physicians were receptive to using the PtDA because it made the consultation more interactive. They were able to elicit the aspects of medication that were important to patients, which allowed them to arrive at an informed decision. The cards were clear and easy to understand for both the patients and physicians. On the other hand, one physician noted that it will take some practice explaining the cards to the patients.

Furthermore, although the use of PtDA by some of the physicians increased consultation time by a few minutes, the trade-off was a more well-informed patient. On the other hand, one physician related that the PtDA even shortened consultation time because the tool provided a more directed yet comprehensive discussion of the treatment options. In addition, physicians also appreciated that they were provided with evidenced-based information as well as key points when explaining the different aspects of the medications.

\section{DISCUSSION}

The paper describes the systematic development of an evidence-based, illustrated PtDA on the treatment of osteoporosis among Filipino postmenopausal women. After testing in clinical encounters, we found the use of PtDA in osteoporosis treatment was well-received and encouraged conversation between Filipino physicians and patients. The integration of decisional needs, clinical expertise and user preference helped the creation of an easy-to-understand PtDA consisting of 5 colored, graphic, easy to understand flashcards consisting of the different aspects of the drugs: efficacy, method of administration, frequency of administration, side effects and cost.

In this study, we have seen that patients were more willing to participate in decision-making when given the opportunity by their primary physician. This is consistent with a systematic review that found that through the years, there has been an increase in patient preference to be involved in decision-making. ${ }^{26}$ There has been a shift in the theoretical model on medical decision-making from paternalistic to shared. It is only in the latter where twoway information communication occurs. ${ }^{27}$ The patient's participation cannot be undervalued because decisional regret, often a result of uninformed decisions or the lack of choices, is associated with lower satisfaction, poor adherence, and reduced quality of life. ${ }^{28,29}$ One of the ways to enhance SDM is through the use of a PtDA.

The development of this PtDA involved several phases. The most challenging of these was the information content, specifically on the side effects of the drugs. It was a recurrent theme among patients that the possible side effects of the drugs might discourage them from taking these drugs. This is similar to one of the qualitative studies done in Iran, wherein some physicians believed that explaining the side effects could raise patient anxiety and subsequently make them quit treatment. ${ }^{30}$ Likewise, a PtDA on osteoporosis treatment that was developed in the Netherlands also had concerns on mentioning serious but usually rare side effects. ${ }^{31}$ To date, it has not yet been established how best to communicate risk of side effects. However, since the goal was to offer a balanced presentation of the benefits and risk of the drugs, it was decided to still highlight these risks in order for patients to have an informed decision.

Another challenge was presenting the data on drug efficacy. We decided to portray the efficacy based on relative risk reduction, as studies have shown that this conveyed better understanding than the number needed to treat. ${ }^{32}$ Given that using relative risk reductions may be perceived to be larger treatment effects, we also presented the baseline risk based on the Fracture Risk Assessment Tool (FRAX ${ }^{\circledR}$ ) score and the absolute risk reduction with treatment in order to balance risk communication..$^{33}$ A separate worksheet was formed in order to better illustrate the efficacy of the drug (Figure 6). This method was also used by Montori et al when they created the Osteoporosis Choice trial. They showed the patient-specific absolute reduction of fracture risk with alendronate using a worksheet, assuming a treatment-related reduction in overall osteoporotic fracture risk of $40 \% .^{13}$

Notably, our osteoporosis PtDA tool was adapted to serve patients from low socioeconomic settings with varied educational backgrounds. The patient who was an elementary school graduate particularly had the most difficult time understanding the PtDA. Communication of health information in simple language is one of the challenges of PtDAs among patients with low literacy and numeracy levels. The use of imagery in the form of icons and probabilistic information expressed in natural frequencies (e.g. 1 in 100) have been acceptable ways to help them understand information better. ${ }^{32,34}$ In addition, PtDA has been shown to benefit disadvantaged people including those from low socioeconomic status and literacy level. In a systematic review investigating the impact of SDM interventions on disadvantaged groups and health inequalities, there was a significant increase in knowledge and a reduction in decisional conflict and uncertainty post-intervention among disadvantaged groups. The participation of patients also increased as they were more involved in discussing options with their physicians. ${ }^{35}$ Although we have not tested the tool in the general population, based on the interviews with patients, the tool made the options more clear, hence the decisions more informed. According to the patients, they would like to have this tool in their future consultations. Similarly, when a decision aid on osteoporosis treatment in Canada was tested, results showed a statistically significant decline in mean decisional conflict scores after using the PtDA. ${ }^{12}$ 
A limitation of this study is that this tool was only tested on a small population of patients and physicians in a tertiary government hospital that caters mostly to patients from low socioeconomic backgrounds. Feasibility studies of the tool in the private setting and for use by other subspecialties involved in the care of osteoporosis will provide a richer information that could be used to further refine the tool. Based on the needs assessment phase, we also emphasize that not all patients are ready to participate in decision-making and would rather leave it to the physician. Some patients are used to the paternalistic model of the physician-patient relationship. Studies have also shown that patients with low literacy levels were less likely to be involved in health decisions and would rather leave it to the decision of the physician. ${ }^{32}$ In the same way, we must also assess the readiness of the physician in incorporating the tool to their usual clinical encounter. Although all agreed that this tool will be helpful in making the options more clear to the patient, it takes skill and practice to incorporate SDM and use of PtDA in the clinic. While the concept of SDM is acknowledged by both parties, it is not yet integral in our daily clinical practice. Therefore, further studies to assess readiness to participate in SDM must also be evaluated in our setting.

In the future, the tool will be tested in an actual field setting in a bigger population with heterogeneous educational and socioeconomic backgrounds to assess its feasibility and eventually implementation. Randomized controlled trials comparing the PtDA versus usual clinical scenario will be conducted to assess transfer of knowledge, level of SDM, decisional conflict, and eventually adherence to treatment.

\section{CONCLUSION}

We were able to develop an illustrated PtDA on the treatment of osteoporosis among Filipino postmenopausal women through the integration of decisional needs assessment, clinical expertise, user preference and iterative revision testing. The tool was acceptable for patients and physicians for their use in the actual clinical setting.

\section{Acknowledgments}

The authors would like to thank Dr. Geraldine Zamora, Dr. Irewin Tabu, Dr. Martha Umali and Dr. Marc Evans Abat for their invaluable input as expert panel. We also express our gratitude to Dr. Victor Montori and his work, for serving as the inspiration in the making of this PtDA. We would also like to acknowledge Flaticon, Freepik and The Noun Project, specifically Mr. Gan Khoon Lay, for their free icons used in the flashcards.

\section{Statement of Authorship}

All authors certified fulfillment of ICMJE authorship criteria.

\section{Author Disclosure}

The authors declared no conflict of interest. The primary author has a Philippine copyright (Registration Number 02020-163) for the decision aid developed and mentioned in this article.

\section{Funding Source}

None.

\section{References}

1. Mithal A, Ebeling P. The Asia-Pacific Regional Audit: Epidemiology, costs \& burden of osteoporosis in 2013. https://www.iofbonehealth. org/sites/default/files/media/PDFs/Regional\%20Audits/2013Asia_Pacific_Audit_0_0.pdf.
2. Tabatabaei-Malazy O, Salari P, Khashayar P, Larijani B. New horizons in treatment of osteoporosis. Daru. 2017;25(1):2. PMID: 28173850. PMCID: PMC5297185. https://doi.org/10.1186/s40199-017-0167-z.

3. The Lancet Diabetes Endocrinology. Osteoporosis: A roadmap to close the treatment gap. Lancet Diabetes Endocrinol. 2018;6(11):833. PMID: 30322720. https://doi.org/10.1016/s2213-8587(18)30292-4.

4. Cosman F, de Beur SJ, LeBoff MS, et al. Clinician's guide to prevention and treatment of osteoporosis. Osteoporos Int. 2014;25(10):2359-81. PMID: 251822281. PMCID: PMC4176573. https://doi.org/10.1007/ s00198-014-2794-2.

5. Dirksen CD. The use of research evidence on patient preferences in health care decision-making: Issues, controversies and moving forward. Expert Rev Pharmacoecon Outcomes Res. 2014;14(6):785-94. PMID: 25135194. https://doi.org/10.1586/14737167.2014.948852.

6. Emkey R, Koltun W, Beusterien $\mathrm{K}$, et al. Patient preference for once-monthly ibandronate versus once-weekly alendronate in a randomized, open-label, cross-over trial: the Boniva Alendronate Trial in Osteoporosis (BALTO). Curr Med Res Opin. 2005;21(12):1895-903. PMID: 16368038. https://doi.org/10.1185/030079905x74862.

7. Lindsay BR, Olufade T, Bauer J, Babrowicz J, Hahn R. Patient-reported barriers to osteoporosis therapy. Arch Osteoporos. 2016;11(1):19. PMID: 27129487. PMCID: PMC4851700. https://doi.org/10.1007/ s11657-016-0272-5.

8. Rabenda V, Reginster JY. Overcoming problems with adherence to osteoporosis medication. Expert Rev Pharmacoecon Outcomes Res. 2010;10(6):677-89. PMID: 21155701. https://doi.org/10.1586/erp.10.76.

9. Keirns CC, Goold SD. Patient-centered care and preference-sensitive decision-making. JAMA. 2015;302(16):1805-6. PMID: 19861674 https://doi.org/10.1001/jama.2009.1550.

10. Joosten EAG, DeFuentes-Merillas L, de Weert GH, Sensky T, van der Staak CPF, de Jong CAJ. Systematic review of the effects of shared decision-making on patient satisfaction, treatment adherence and health status. Psychother Psychosom. 2008;77(4):219-26. PMID: 18418028. https://doi.org/10.1159/000126073.

11. Stacey D, Légaré F, Col NF, et al. Decision aids for people facing health treatment or screening decisions. Cochrane Database Syst Rev. 2014;(1):CD001431. PMID: 24470076. https://doi.org/10.1002/14651858. cd001431.pub4.

12. Cranney A, O'Connor AM, Jacobsen MJ, et al. Development and pilot testing of a decision aid for postmenopausal women with osteoporosis. Patient Educ Couns. 2002;47(3):245-55. PMID: 12088603. https://doi.org/10.1016/s0738-3991(01)00218-x.

13. Pencille LJ, Campbell ME, Van Houten HK, et al. Protocol for the osteoporosis choice trial. A pilot randomized trial of a decision aid in primary care practice. Trials. 2009;10:113. PMID: 20003299. PMCID: PMC2796658. https://doi.org/10.1186/1745-6215-10-113.

14. Montori VM, Shah ND, Pencille LJ, et al. Use of a decision aid to improve treatment decisions in osteoporosis : The osteoporosis choice randomized trial. Am J Med. 2011;124(6):549-56. PMID: 21605732. https://doi.org/10.1016/j.amjmed.2011.01.013

15. O'Connor A, Llewellyn-Thomas H, Stacey D, eds. IPDAS collaboration background document. 2005. http://ipdas.ohri.ca/IPDAS_Background. pdf

16. Royal Osteoporosis Society. Drug treatments for osteoporosis: Zoledronic acid (Aclasta). https://theros.org.uk/media/2cmhexi4/roszoledronic-acid-fact-sheet-january-2016.pdf.

17. Royal Osteoporosis Society. Drug treatments for osteoporosis: Parathyroid hormone treatment [teriparatide (Forsteo Movymia, Terrosa)]. https://theros.org.uk/media/yt1loo5s/ros-parathyroidhormone-treatment-fact-sheet-december-2019.pdf.

18. Royal Osteoporosis Society. Drug treatments for osteoporosis: Risedronate (risedronate sodium, Actonel). https://theros.org.uk/ media/txupx3ve/ros-risedronate-fact-sheet-january-2016.pdf.

19. Royal Osteoporosis Society. Drug treatments for osteoporosis: Raloxifene (Evista). https://strwebstgmedia.blob.core.windows.net/ media/xmfjjuek/raloxifene-evista-fact-sheet-june-2017.pdf.

20. Royal Osteoporosis Society. Drug treatments for osteoporosis: Ibandronate (Bonviva). https://strwebstgmedia.blob.core.windows. net/media/3n3ni0w0/ibandronate-bonviva-fact-sheet-january2016.pdf.

21. Royal Osteoporosis Society: Drug treatments for osteoporosis Denosumab (Prolia). https://strwebstgmedia.blob.core.windows.net/ media/sxif4dxc/denosumab-prolia-fact-sheet-octobe-2017.pdf.

22. Royal Osteoporosis Society. Drug treatments for osteoporosis: Alendronate (alendronic acid or Fosamax). https://theros.org.uk/ media/lcwnpxth/ros-alendronic-acid-and-osteoporosis-fact-sheetaugust-2017.pdf.

23. Jansen JP, Bergman GJD, Huels J, Olson M. The efficacy of bisphosphonates in the prevention of vertebral, hip, and nonvertebralnonhip fractures in osteoporosis: A network meta-analysis. Semin Arthritis Rheum. 2011;40(4):275-84.e2. PMID: 20828791. https://doi. org/10.1016/j.semarthrit.2010.06.001.

24. Cummings SR, San Martin J, McClung MR, et al. Denosumab for prevention of fractures in postmenopausal women with osteoporosis. 
N Engl J Med. 2009;361(8):756-65. PMID: 19671655. https://doi. org/10.1056/nejmoa0809493.

25. Neer RM, Arnaud CD, Zanchetta JR, et al. Effect of parathyroid hormone (1-34) on fractures and bone mineral density in postmenopausal women with osteoporosis. N Engl J Med. 2001:344(19):1434-41. PMID: 11346808. https://doi.org/10.1056/nejm200105103441904.

26. Chewning B, Bylund CL, Shah B, et al. Patient preferences for shared decisions: A systematic review. Patient Educ Couns. 2012;86(1):918. PMID: 21474265. PMCID: PMC4530615. https://doi.org/10.1016/ j.pec.2011.02.004.

27. Bae JM. Shared decision-making: relevant concepts and facilitating strategies. Epidemiol Health. 2017:39:e2017048. PMID: 29092391. PMCID: PMC5733387. https://dx.doi.org/10.4178\%2Fepih.e2017048.

28. Becerra-Pérez MM, Menear M, Turcotte S, Labrecque M, Légaré F. More primary care patients regret health decisions if they experienced decisional conflict in the consultation: A secondary analysis of a multicenter descriptive study. BMC Fam Pract. 2016;17(1):156 PMID: 27832752. PMCID: PMC5103443. https://doi.org/10.1186/ s12875-016-0558-0.

29. Becerra-Pérez MM, Menear M, Brehaut JC, Légaré F. Extent and predictors of decision regret about health care decisions: A systematic review. Med Decis Making. 2016;36(6):777-90. PMID: 26975351. https://doi.org/10.1177/0272989x16636113.

30. Rashidian H, Nedjat S, Majdzadeh R, et al. The perspectives of Iranian physicians and patients towards patient decision aids: A qualitative study. BMC Res Notes. 2013:6:379. PMID: 24066792. PMCID: PMC3849268. https://doi.org/10.1186/1756-0500-6-379.
31. Hiligsmann $\mathrm{M}$, Ronda $\mathrm{G}$, van der Weijden $\mathrm{T}$, Boonen $\mathrm{A}$. The development of a personalized patient education tool for decisionmaking for postmenopausal women with osteoporosis. Osteoporos Int. 2016;27(8):2489-96. PMID: 27048388. PMCID: PMC4947108. https://doi.org/10.1007/s00198-016-3555-1.

32. McCaffery KJ, Smith SK, Wolf M. The challenge of shared decision making among patients with lower literacy: A framework for research and development. Med Decis Making. 2010;30(1):35-44. PMID: 19692709. https://doi.org/10.1177/0272989x09342279.

33. Akl EA, Oxman AD, Herrin J, et al. Using alternative statistical formats for presenting risks and risk reductions. Cochrane Database Syst Rev. 2011;2011(3):CD006776. PMID: 21412897. PMCID: PMC6464912. https://doi.org/10.1002/14651858.cd006776.pub2.

34. Garcia-Retamero R, Cokely ET. Communicating health risks with visual aids. Curr Dir Psychol Sci. 2013;22(5):392-9. https://doi. org/10.1177\%2F0963721413491570.

35. Durand MA, Carpenter L, Dolan H, et al. Do interventions designed to support shared decision-making reduce health inequalities? A systematic review and meta-analysis. PLoS One. 2014:9(4):e94670. PMID: 24736389. PMCID: PMC3988077. https://doi.org/10.1371/ journal.pone.0094670.

Authors are required to accomplish, sign and submit scanned copies of the JAFES Author Form consisting of: (1) Authorship Certification, that authors contributed substantially to the work, that the manuscript has been read and approved by all authors, and that the requirements for authorship have been met by each author; (2) the Author Declaration, that the article represents original material that is not being considered for publication or has not been published or accepted for publication elsewhere, that the article does not infringe or violate any copvrights or intellectual property rights, and that no references have been made to predatory/ suspected predatory journals; (3) the Author Contribution Disclosure, which lists the specific contributions of authors; and (4) the Author Publishing Agreement which retains author copyright, grants publishing and distribution rights to JAFES, and allows JAFES to apply and enforce an Attribution-Non-Commercial Creative Commons user license. Authors are also required to accomplish, sign, and submit the signed ICMJE form for Disclosure of Potential Conflicts of Interest. For original articles, authors are required to submit a scanned copy of the Ethics Review Approval of their research as well as registration in trial registries as appropriate. For manuscripts reporting data from studies involving animals, authors are required to submit a scanned copy of the Institutional Animal Care and Use Committee approval. For Case Reports or Series, and Images in Endocrinology, consent forms, are required for the publication of information about patients; otherwise, appropriate ethical clearance has been obtained from the institutional review board. Articles and any other material published in the JAFES represent the work of the author(s) and should not be construed to reflect the opinions of the Editors or the Publisher.

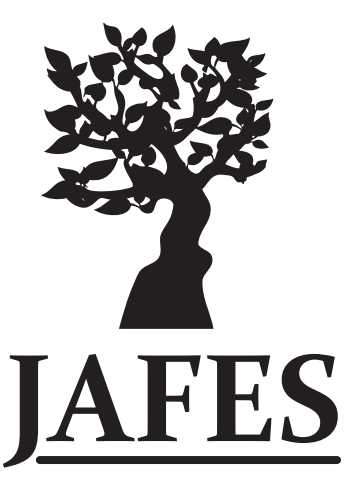

\section{Send your paper to the publication pathway. Instructions to Authors at www.ASEAN-endocrinejournal.org.}

